\title{
Cultural competence in mental health care: a review of model evaluations
}

\author{
Kamaldeep Bhui*1, Nasir Warfa1, Patricia Edonya1, Kwame McKenzie ${ }^{2}$ and \\ Dinesh Bhugra ${ }^{3}$
}

Address: ${ }^{1}$ Centre for Psychiatry, Barts and The London, Queen Mary's School of Medicine and Dentistry, Old Anatomy Building, Charterhouse Square, London EC1M 6BQ, UK, 2 Department of Mental Health Sciences, Royal Free \& University College School of Medicine, University of London, UK and ${ }^{3}$ Department of Cultural Psychiatry, Institute of Psychiatry, King's College, University of London, UK

Email: Kamaldeep Bhui* - k.s.bhui@qmul.ac.uk; Nasir Warfa -n.warfa@qmul.ac.uk; Patricia Edonya - patricia.edonya@islington.gov.uk; Kwame McKenzie - k.mckenzie@medsch.ucl.ac.uk; Dinesh Bhugra - d.bhugra@iop.kcl.ac.uk

* Corresponding author

Published: 31 January 2007

BMC Health Services Research 2007, 7:15 doi:10.1186/1472-6963-7-15

This article is available from: http://www.biomedcentral.com//472-6963/7//5

(C) 2007 Bhui et al; licensee BioMed Central Ltd.

This is an Open Access article distributed under the terms of the Creative Commons Attribution License (http://creativecommons.org/licenses/by/2.0), which permits unrestricted use, distribution, and reproduction in any medium, provided the original work is properly cited.
Received: 4 August 2006

Accepted: 31 January 2007

\begin{abstract}
Background: Cultural competency is now a core requirement for mental health professionals working with culturally diverse patient groups. Cultural competency training may improve the quality of mental health care for ethnic groups.

Methods: A systematic review that included evaluated models of professional education or service delivery.

Results: Of 109 potential papers, only 9 included an evaluation of the model to improve the cultural competency practice and service delivery. All 9 studies were located in North America. Cultural competency included modification of clinical practice and organizational performance. Few studies published their teaching and learning methods. Only three studies used quantitative outcomes. One of these showed a change in attitudes and skills of staff following training. The cultural consultation model showed evidence of significant satisfaction by clinicians using the service. No studies investigated service user experiences and outcomes.
\end{abstract}

Conclusion: There is limited evidence on the effectiveness of cultural competency training and service delivery. Further work is required to evaluate improvement in service users' experiences and outcomes.

\section{Background}

Health professionals are now more aware of the challenges they face when providing health care to a culturally and racially diverse population [1]. Despite concern about ethnic disparities of access to culturally appropriate mental health care, and calls for cultural competency training to be mandatory, there is little information about the effectiveness of cultural competency training in mental health settings [2-4]. It is well established that in order to provide culturally competent care, knowledge of cultural beliefs, values and practices is necessary otherwise health practitioners can easily fall prey to errors of diagnosis, inappropriate management and poor compliance [5]. Training curricula for medical, nursing and social work students now generally include lectures and course work on cultural competency in health care provision. Post- 
graduate training is also being revised (for example in the UK the Royal College of Psychiatrists) to incorporate cultural influences on mental health care. Despite this progress, a recent tragedy in the UK expedited the acceptance of policies to promote cultural competency training. A psychiatric inpatient was medicated under compulsory legislation and died while being restrained following a period during which he was subjected to racial abuse from another patient. The subsequent inquiry concluded that better training was necessary for the management of imminent violence and for staff to develop cultural competence in care provision [3].

Although such recommendations are laudable, there appear to be several problems with such an approach. There is considerable confusion about what constitutes cultural competence. For example, it may be narrowly interpreted to mean better knowledge of the cultural beliefs and practices of a specific cultural group, with little attention to how culture modifies illness perceptions, illness behaviour, and acceptability of specific interventions. Cultural competency is somehow expected to emerge if the racial and ethnic mix of the workforce is representative of the local population. Not surprisingly, working practices following standardised professional trainings remain similar among staff from different ethnic groups because of the common pattern of training. Indeed, a patient and a health professional, ostensibly belonging to the same ethnic group because of shared country of origin, may actually differ in terms of social class, religious practices, languages, and cultural beliefs about illness and recovery. Despite a growing body of health and educational policies that prioritise cultural competency in health care provision, there is surprisingly little agreement on the meaning of cultural competence training or knowledge about its effectiveness.

\section{Aims}

In this review we seek to: define the meaning of cultural competence in mental health settings, describe models of cultural competence which have been evaluated in mental health settings, and assess the evidence for effectiveness by reviewing studies that implemented a model of cultural competence and then evaluated its effectiveness.

\section{Methods}

All accounts of cultural competency published in English since 1985 were identified. This date was applied to ensure relevance to recent practice and profiles of ethnic groups for whom the training is intended to improve outcomes. The searches were undertaken between January 2004 and June 2004. The titles and abstracts of papers were reviewed against inclusion criteria:
- showed implementation of a cultural competence model of mental health care AND

- provided some evaluation data for a cultural competency model of service provision or training AND/OR included an evaluation of adherence to a pre-defined model of cultural competence in mental health services

Papers meeting these criteria were called A papers (listed in Table 1). Other relevant papers were not extracted but read for background information, and for placing some of the findings in a wider context. We included all papers published in English language that were about adults with mental illness. The literature search including the following databases: Ingenta, Medline via Ovid, Medline via Pubmed, Medline Plus, Health Outcomes, HealthPromis, HSTAT, DocDat, National Research Register, NLM Gateway, Cam, ReFer and Zetoc. Research Phrases/terms included combinations of the following: Cultural Competence, Cultural Capability, Cultural Sensitivity, Mental Health, Mental Healthcare, Mental Health settings, Best practice, Cross Cultural Mental Health and Cross Cultural Psychiatry. Websites known to include cultural competency or educational materials were also searched [6-15].

Forward and backward citation tracking was undertaken on A papers to identify any further papers of relevance. We also asked two experts to review the search findings, and recommend any other publications. This yielded a $\mathrm{PhD}$ thesis and one paper, but neither met our inclusion criteria as they did not include an evaluation. We aimed to include quantitative and qualitative studies. Two researchers reviewed and extracted data from each of the 9 papers; disagreements on the extracted data were resolved by consensus. Information about the studies was extracted and tabulated, including year of study, author, type of study, country of study, and reference populations (Table 1). We undertook a narrative synthesis of the data that is suitable for observational studies where meta-analysis is inappropriate $[16,17]$.

\section{Results}

A total of 1554 publications were identified; of these 109 were selected for further scrutiny on the basis of screening the abstract and titles; only 9 of these met our basic inclusion criteria. These studies implemented models of cultural competence that were evaluated by qualitative or participatory methods, or presented an evaluation of an intervention to improve cultural competency. All studies were based in North America. Many other models of cultural competency were reported in other papers that did not meet our inclusion criteria; we did not review these as there was no evaluation to support them as a model for real services settings. Most of these additional papers 
Table I: Descriptive information on study populations, definitions, models of cultural competence, and outcomes

\begin{tabular}{|c|c|c|c|c|}
\hline Study & Nature of Evidence & Definitions of CC & Reference population & Models of cultural competence \\
\hline Ferguson (2003) & $\begin{array}{l}\text { Setting of standards for curriculum for cultural } \\
\text { diversity in the years } 1999 \text { and } 2000 \text {. } \\
\text { Evaluation of programme of teaching, and of } \\
\text { cultural competence: change in attitudes and } \\
\text { behaviour }\end{array}$ & $\begin{array}{l}\text { Cultural competence is a dynamic continuum } \\
\text { consisting of seven stages: Listen, Elicit, Assess, } \\
\text { Recommend, Negotiate (LEARN) }\end{array}$ & $\begin{array}{l}15 \text { New England \& New York Medical Schools, USA } \\
137 \text { participants ( } 83 \text { women, } 42 \% \text { family medicine } \\
\text { specialists, } 52 \% \text { less than } 10 \text { years in practice. }\end{array}$ & $\begin{array}{l}\text { Community Curriculum Model } \\
\text { Module I: CC and the role of the physician } \\
\text { Module 2: teaching skills of CC } \\
\text { Module3: Moving beyond cultural awareness }\end{array}$ \\
\hline Hadwiger (1999) & $\begin{array}{l}\text { Cultural competence in critical care nursing } \\
\text { practice. } \\
\text { Narrative responses to case scenarios used to } \\
\text { develop skills, self reflection, and improved quality } \\
\text { of care plans }\end{array}$ & $\begin{array}{l}\text { Process of working with patients from different } \\
\text { cultural background than one's own } \\
\text { To reflect on beliefs and assumptions } \\
\text { Negotiate a plan of care without use of stereotypes } \\
\text { Problem solving and writing competencies }\end{array}$ & Nursing Students in a Midwest Community, USA & $\begin{array}{l}\text { Campinha-Bacote Model [30][37] } \\
\text { 1. Cultural awareness } \\
\text { 2. Cultural Knowledge } \\
\text { 3. Cultural Skill } \\
\text { 4. Cultural Encounters } \\
\text { One case over } 6-8 \text { week period: } 4 \text { case scenarios }\end{array}$ \\
\hline Siegel et al (2003) $\dagger$ & $\begin{array}{l}\text { Performance measures of cultural competency } \\
\text { were selected and benchmarked in } 21 \text { health care } \\
\text { organisations inUS } \\
\text { Delphi exercise: experts asked to rate importance, } \\
\text { feasibility and reliability of indicators; these were } \\
\text { then reviewed to ensure they addressed CLAS } \\
\text { (cultural and linguistically appropriate services) } \\
\text { standards set by US Dept. Health and Human } \\
\text { Services }\end{array}$ & $\begin{array}{l}\text { The set of congruent behaviors, attitudes, skills, } \\
\text { policies and procedures that enable the } \\
\text { organization's caregivers to work effectively and } \\
\text { efficiently in cross/multicultural situations }\end{array}$ & $\begin{array}{l}\text { Mental Health Care Organizations in the USA } \\
\text { Expert panel of four major ethnic groups in US: African } \\
\text { American, Hispanic, Asian Indian, and Asian American } \\
\text { Survey data from } 21 \text { mental health organizations } \\
\text { Telephone interviews of services already implementing } \\
\text { cultural competency benchmarks. } \\
\text { Key informant interviews with } 21 \text { best practice } \\
\text { organisations: } 15 \text { administrative sites and } 8 \text { service entities }\end{array}$ & $\begin{array}{l}\text { Phase I: develop a framework of key domains and select } \\
\text { performance measures of cultural competence: (I) needs } \\
\text { assessment; (2) information exchange; (3) services; (4) human } \\
\text { resources; (5) policies and plan, (6) linked to outcomes. } \\
\text { Three organisational levels: (I) administrative (state mental } \\
\text { health authority or a managed care entity); (2) service delivery entity } \\
\text { and (3) individuals involved directly or indirectly with the delivery of } \\
\text { care. Phase 2: Measures reduced to a manageable size }\end{array}$ \\
\hline Kim-Godwin (200I) & $\begin{array}{l}\text { Concept analysis by } 13 \text { community nurses and } \\
\text { nurse experts }\end{array}$ & $\begin{array}{l}\text { Key domains of cultural competence: I)Caring } \\
\text { 2)Cultural sensitivity, 3)Cultural knowledge 4) } \\
\text { cultural skills are' }\end{array}$ & $\begin{array}{l}\text { In } 1996 \text { scale tested on } 192 \text { senior undergraduate and } \\
\text { graduate nursing students in two Soouth Eastern US centres. } \\
\text { Community Health Nurses in Idaho. } \\
\text { In } 1998 \text {, in depth interviews with } 13 \text { nurses }(8 \text { community } \\
\text { health nurses and } 5 \text { community nurse experts). }\end{array}$ & Culturally Competence Community Care \\
\hline Kondrat et al (1999) & $\begin{array}{l}\text { Semi-structured interviews with } 64 \text { workers at } 4 \\
\text { different mental health agencies/case record } \\
\text { analysis of } 24 \text { consumers } \\
\text { Sites matched on per capita expenditure, } \\
\text { proportion of African American Clients, } \\
\text { proportion of minority staff } \\
\text { Sites picked where minorities doing better on } \\
\text { community tenure (benchmark agencies) and } \\
\text { compared with sites where they were not doing so } \\
\text { well }\end{array}$ & $\begin{array}{l}\text { The best practice approach is pragmatic, practice } \\
\text { driven, and results oriented. }\end{array}$ & $\begin{array}{l}\text { Community Mental Health Agencies in Ohio, USA } \\
\text { Field observations: Intensive observations of } 3 \text { days per } \\
\text { week for a period of } 2 \text { weeks } \\
\text { Then } 2 \text { days per week for a period of } 2 \text { weeks } \\
\text { Then I day per week, for I } 12 \text { weeks } \\
\text { Semi-structured interviews: administrators ( } 3 \text { or } \\
\text { more), team leaders ( } 2 \text { or more), managers, } 6 \text { clients, } 6 \\
\text { carers at each of the four sites (snowballing technique) } \\
\text { Document analysis: Case records of } 24 \text { consumers ( } 12 \\
\text { African American and } 12 \text { Caucasian) for decision nodes in } \\
\text { care. " years of entries per client. }\end{array}$ & Benchmarking Research Model \\
\hline Kirmayer et al (2003) & $\begin{array}{l}\text { Participant observation \& analysis of case reports } \\
\text { of first } 100 \text { referrals }\end{array}$ & $\begin{array}{l}\text { Cultural consultation models suggest a mechanism } \\
\text { to address the impact of cultural diversity on } \\
\text { mental health problems. }\end{array}$ & Mental health Service providers, Montreal, Canada & $\begin{array}{l}\text { Cultural Consultation Model based on DSM-IV cultural formulation, } \\
\text { using cultural consultants and culture brokers. Three options: I) I- } \\
3 \text { meetings with patient, and brief reportt, phone calls, case } \\
\text { conference to transmit immediate recommendations, subsequent } \\
\text { more detailed report; 2) Cultural consultant discusses case with } \\
\text { referring consultant without seeing patient directly. Clinical case } \\
\text { conference may ensue; 3) Consultant meets with referring } \\
\text { community organisations, without directly seeing community } \\
\text { members. II a clinical case conference, community organisations } \\
\text { express problems in engaging or providing a service for a specific } \\
\text { cultural group. }\end{array}$ \\
\hline Frusti et al (2003) & $\begin{array}{l}\text { Qualitative data: individual }(n=43) \text { senior staff } \\
\text { including directors and managers; and focus group } \\
\text { interviewws with staff, with efforts to include } \\
\text { minority groups } \\
\text { Quantitative data from documents from the } \\
\text { nursing organisation and organisation as a whole, } \\
\text { seeking evidence of diversity competence }\end{array}$ & $\begin{array}{l}\text { Diversity Competence Model assessment: diversity } \\
\text { competence is defined as an individual's ability to } \\
\text { respect each person's uniqueness. Goals of } \\
\text { marketplace success, ability to compete, enhanced } \\
\text { overall performance, and increased capability of all } \\
\text { staff }\end{array}$ & Nursing Workforce & $\begin{array}{l}\text { Diversity Competency Model: } \\
\text { 1) Drivers } \\
\text { 2) Linkages } \\
\text { 3) Cultures, } \\
\text { 4) Measurement, } \\
\text { 5) all held together by Commitment }\end{array}$ \\
\hline Stork et al (200I) & $\begin{array}{l}\text { Case study of five US states To assess } \\
\text { implementation of cultural competence provisions } \\
\text { in behavioural managed care contracts. }\end{array}$ & $\begin{array}{l}\text { Cultural Competence: "Agencies, programs and } \\
\text { services that are responsive to the cultural, racial } \\
\text { and ethnic differences of the populations they } \\
\text { service" (CASSP, 1984) } \\
\text { Culturally competent professionals are those who } \\
\text { have "the ability to serve individuals of diverse } \\
\text { backgrounds" [38] }\end{array}$ & $\begin{array}{l}\text { Exploratory study of how five states of average population } \\
\text { distribution and resources implement, monitor and enforce } \\
\text { contractual obligations for culturally competent provision } \\
\text { in Medical managed care. }\end{array}$ & $\begin{array}{l}\text { State managed behavioural organisations Federal regulations about } \\
\text { cultural competence derive from Disability Act of } 1990 \text {, Civil Rights } \\
\text { Act that prohibibs discrimination. } \\
\text { Interpretation of these rules: translation services, language } \\
\text { assistance, quality assurance rules, including grievance procedures, } \\
\text { to have capacity and appropriate range of services to serve } \\
\text { enrolees, as well as sufficient disciplinary mix, geographic } \\
\text { distribution). } \\
\text { Extent of contractual provisions, monitoring, flexibility in provider } \\
\text { organisation. }\end{array}$ \\
\hline $\begin{array}{l}\text { US Department of } \\
\text { Health and Human } \\
\text { Services (HRSA) }\end{array}$ & $\begin{array}{l}\text { Participant observation/group discussions/ } \\
\text { documentary analysis } \\
\text { Developed an assessment profile for organisational } \\
\text { cultural competence, and evaluated its } \\
\text { performance in health care organisations across a } \\
\text { range of size, expenditure, populations served, and } \\
\text { cultural competency levels }\end{array}$ & $\begin{array}{l}\text { Cultural competence is a critical factor in providing } \\
\text { relevant services to nations growing culturally } \\
\text { ethnically diverse population }\end{array}$ & USA Health Care Organizations & $\begin{array}{l}\text { Organizational Cultural Competence Assessment Profile: gives } \\
\text { structure, process and outcome indicators for each of the OMH } \\
\text { domains of organisational cultural competency } \\
\text { Model Domains: I)Values and attitudes, 2)Cultural sensitivity, 3) } \\
\text { Communication, 4) PPlicies and Procedures, 5) Training and Staff } \\
\text { development, 6. Facility characteristics, 7) Intervention and } \\
\text { treatment model, 8) Family and community participation, 9) } \\
\text { Monitoring, evaluation and research }\end{array}$ \\
\hline
\end{tabular}

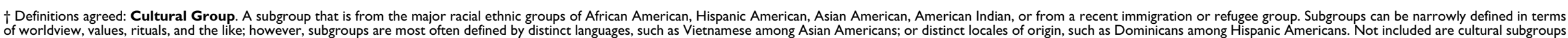

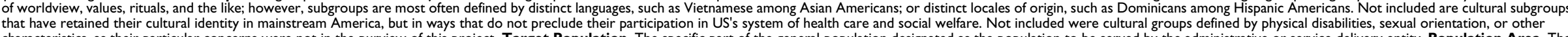
列 geographical area designated as the area to be served by the administrative or service delivery entity. 
expressed opinions or experiences of teaching and training in cultural competence.

\section{Scope of Papers}

Five papers were on cultural competency for physicians and nurses [18-20], multidisciplinary teams [21], and medical students [22]. Five papers included organisational aspects of cultural competency; these referred to the implementation of an assessment and performance framework [4], assessing and implementing measurable benchmarks for performance management $[23,24]$, interpretation of state legislation, contract language and monitoring for impacts on cultural competency [25]; one paper explored organisational drivers that promote change, whilst ensuring measurement of performance, and that there was a change of organisational culture; this paper also explored how organisations integrated different programmes of activity [16]. One government initiative [4] relied on standards set by the Office of Minority Health [26], called the Culturally and Linguistically Appropriate Services Standards (or CLAS Standards; see Table 1).

\section{Methods Used in Studies}

The study methods varied widely, with outcomes that varied across studies; most studies used an action research process, and none used a randomised control trial design. The methodological variability and reliance on exploratory designs precluded meta-analyses, and even quality assignment, as some studies either did not report their analytic methods in enough detail or evolved their methods during the study. Some only measured adherence to a template of cultural competence, rather than the clinical outcome of adherence to a cultural competency model.

\section{Definitions of Culture Competence}

The definitions proposed in each of the 9 papers were tabulated (Table 1). We present here a synthesis of the key characteristics. Cultural competence included a set of skills or processes that enable mental health professionals to provide services that are culturally appropriate for the diverse populations that they serve. This definition was focussed on an outcome, and included attention to obvious language differences in the consultation, as well as how culture influences attitudes, expressions of distress, and help seeking practices. Consequently, it was suggested that clinical procedures and policies should reflect these. Showing respect for patients' cultural beliefs and attitudes was an important component, especially when their views opposed or differed from the professionals' views. Emphasis was given to a genuine willingness and desire to learn about other cultures, rather than this simply being a managerial requirement. The definitions indicate a common aim, to increase performance and the capabilities of staff when providing service to ethnic minorities. Most studies gave a definition of cultural competence before their evaluation, but one study [25] reported that different definitions were used in different US states (see Table 2).

\section{Mandatory or Discretionary}

Table 1 \& 2 set out the key components of the models and present the outcome data. The studies of individual professions took an educational approach, subjecting each group to an analysis of how best to teach and learn about culture: the key findings include the need for a desire to learn about other cultures and that this could not be mandated. Three papers recommended that training be discretionary $[22,18,24]$, whereas, like UK policy, one paper recommended a compulsory process [23]. Actual encounters with other cultural groups were considered important in all studies.

\section{Teaching and Learning Methods}

Only three studies published their teaching and learning methods. One model of cultural competency recommended participant observation, analysis of case reports, consultation and conferences around specific clinical problems [19]. Another [18] recommended discussing and writing about case histories and paying attention to the narratives. Hadwiger's model was developed for nursing working in critical care settings; this deployed interactive lectures and small group teaching with role-play exercises and patient centred interviews to enhance cultural understanding [20]. Only three studies actually followed up subjects to assess changes in behaviour or adherence to a model of cultural competency following an intervention $[19,22,23]$.

\section{Organisational Processes}

Four studies evaluated organisational approaches [4,23$25]$, but each study focussed on different processes. Siegel et al developed performance indicators and tested them for feasibility and value within a performance framework for 21 health care organisations [23]. Kondrat et al identified characteristics of better performing culturally competent organisations (called benchmark agencies), where these distinguished them from less culturally competent organisations (comparison agencies): a pro-agency attitude among staff, openness and flexibility of provision, consistent, pro-active and supportive supervision, and team based functioning and decision making were all essential [24]. This study also showed that race and culture were rarely considered in care provision.

The US Dept of Health and Human Services developed a performance framework using the nine domains for cultural competent health care provision proposed by the Office of Minority Health [26]. These include organisational and individual level processes, including a perform- 
Table 2: Main findings: evaluation and outcomes

\section{Study}

Ferguson (2003) Likert ratings ( $1-5)$ of overall value, clarity of objectives, instructor For second cohort $(2000, \mathrm{~N}=55)$

Hadwiger (1999) Cultural Sensitivity (40\% of course marks) Evidence of context of own cultural background considered

Ethnocentric attitude

Egalitarian relationship

rust in relationships

Respect for patient during hypothetical negotiations

Manner of addressing hypothetical patients

Process (30\% of course marks)

Siegel et al (2003) † For each level and domain, experts identified key performance indicators

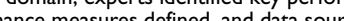
163 indicators

231 measures

Without a formal commitment to the development of a process and the Reduced to 85 measures

Kim-Godwin (2001) Literature review and concept analysis lead to 3 constructs that were ms, 2) health outcomes, and 3) cultura competence scale ratings.

Kondrat et al (1999) Nature of interactions between service providers and Caucasian and African American consumers with SMI Themes: Types and locations of service delivery Structure of delivery services

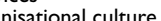

rocess

Perceptions of interactions, processes and decisions Analysis based on 700 observations across four sites Constant comparison analyses

\section{Outcomes}

Showed high scores on all of these: means 4.1 to 4.4 for each domain, and for two year bands 1999 and 2000

Intention to change: $M I: 5.4 \%(n=55), M 22.48 .1 \%(n=54), M 3: 30.2 \%(n=43)$
Actual Change in behaviour: MI: $16.6 \%(n=42), M 2: 21.4 \%(n=42), M 3:-$

Nursing students were able to become more aware of how their own culture affects the nursing care Able to refine cultural competence skills using hypothetical cases and narrative writing
Actual marks or origins of students not given

Administrative:

Services. $53 \%$ had put into place services that had been adapted or developed for specific cultural groups.
CC Outcomes. $60 \%$ of administrative entities indicated that outcome groups.

CC Training and Education.

$73 \%$ indicated staff members receive ongoing education and training related to $\mathrm{CC}$.
$87 \%$ selected, developed, and/or provided CC training materials to agencies under their purview but only one provided financial assistance to agencies under its purview for conducting CCT Services. $87 \%$ of the service entities indicated that they had services adapted or developed for specific cultural groups. $29 \%$ of these, providing culture-specific
services was the mission of the agency; while for the remaining $71 \%$, culture-specific services had been put in place in response to the perceived needs of clients in the Community. Training and Education.

$75 \%$ indicated that staff of receive ongoing education and training on CC. $87 \%$ said all new employees receive CC education and training as part of their orientation.

75\% said that professional education (for example, grand rounds) included racial/ethnic/cultural issues.
CC Outcomes. Outcome measure data were collected inconsistently at the five agencies responding to this question, but all conducted consumer satisfaction CC Outcomes. Outcome measure data were collected inconsistently at the five agencies responding to this question, but all conducted consumer satisfaction
surveys. Sixty percent of those responding indicated that the outcome measures could be analyzed for specific cultural groups. $50 \%$ said that CC was included in
staff performate evaluations.

In factor analyses, cultural knowledge emerged as a components of cultural sensitivity and cultural skills

All I3 participants reported that cultural competent care resulted in positive health outcomes in their practice. Specifically, increases in prenatal visits, higher rates accounts not presented, only surmises findings).

All four agencies incorporated policies to support diversity, yet outcomes for diverse clients varied.

II clusters of activity:

Differentiating: $B>C$
1. Agency work culture: pro-agency culture:

2. Openness/boundary flexibility

3. Prevalent supervisory style: consistent, pro-active, and supportive

Non-Differentiating

5. Attitudes towards clients:

6. Demonstration of programme commitment to diversity

8. Diversity as a clinical is

9. Clinical orientation

10. Level of interdisciplinary work

There was little evidence than 
Specialized cultural consultation services can play a major role in educating clinicians and in developing innovative intervention strategies Cases seen by the team demonstrated the impact of cultural misunderstandings: incomplete assessments, incorrect diagnoses, inadequate or inappropriate treatments, and failed treatment alliances.

the service reported high rates of satisfaction, but many indicated a need for longer term follow up.

$21 \%$ increased knowledge of social, cultural or religious aspects of cases

$48 \%$ : improved treatments

\%: improved communications, empathy, understanding, therapeutic alliance

4\%: lack of treatm

\% concerns abou inappropriateness of recommended resources

\% too

Frusti et al (2003) Consultant employed to assess drivers, linkages, culture and measurement strengths and weaknesses of organisatio

Stork et al

Used data from Rosenbaum (1999) study of cultural competence in manage care contracts. requirements for service provision. Open ended interviews with officials in five states to examine writte cultural competence requirements.

Purposive sample of states that

) that had contract with cultural competence provisions 2) more comprehensive requirements than other states, reflecting early in resources and populations Tho could talk in depth about contracts Rosenbaum reported on 37 states, of these 27 had cultural competency ecific wording about practices rights to culturally competent sevices States selected because of geographic, ethnic and racial diversity Interview: definition of $\mathrm{CC}$

Contract language/standards

ence standar

enrolment/satisfaction/service use by ethnic/racial groups

Organisational cultural competence assessment profile assesses domains, focus areas and indicators

Domains: As in Table I.
For each domain there are Indicators which have a) structure, b) process and c) outcome

Drivers: 1) nursing diversity committee promotes supportive work environment by sponsoring educational activities \& newsletter

2) Nursing recruitment and retention committee

3) Transcultural patient care committee, provides up to date resources about influence of culture on health

Linkages:I) Managers and staff share department committee responsibilities, and feed into a shared decision making process

ual planning to identify shared gols, and recruitment targets national and local nursing organisation Culture: I) education and orientation to culture of nursing groups

(a) trusted, $75 \%$ of 2) primary values: needs of patients first, best nursing care in the world Measurement: Recruitment data, retention data, compared with national benchmarks

Lack of indicators for cultural competence, reluctant to enforce existing standards, disagreement over costs, lack of constituency in training and tracking 4 of five states included their own definitions of cultural competence in their contracts

- Relate to client with sensitivity, understanding, respect for clients' culture

- Understanding social, linguistic, ethnic and behavioural characteristics of a community or a population and the ability to translate systematically, that knowledge knowledge/resources, collaborate with community re provisions and delivery, commit to cross cultural training, develop policies to provide relevant, effective, programs for diverse populations

- Ability to serve individuals of all ages, ethnic groups, in a manner appropriate to their age and unique cultural background.

- A set of congruent behaviours, attitudes and practices and policies that are formed within an agency and among professionals that enable the system, agency and
professionals to work respectfully, effectively, responsibly, in diverse situations. Essential elements include: valuing diversity, understanding dynamics of difference,

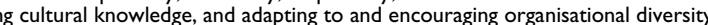

Themes identified: contract language, contract deliverables, procedures for monitoring and oversight, data collection, provider assessments Contractual deliverables: submit a plan to include translations of written material and access to interpreters at no extra cost, legally mandated.

Oversight/agency: assign responsibility to a specific agency.
Oversight mechanisms: readiness reviews, site reviews, before roll out. Complaint tracking, consumer satisfaction surveys. Collecting client data: three stated did not collect enrolment data, disenrollment, provider changes, service use or satisfaction by race/ethnicity. Two states can
assess requests to change provider by ethnicity, and whether change requested is a result of language problems. None of the states used the cultural data on their client to indicate lack of cultural competence. No state asks clients to rate their cultural competence of provision

Assessment of CC: determined by provider to MCO/MBHO documentation of training, available ;personnel, representative services as contract deliverables

Findings suggest that the Assessment Profile can be useful even in its current form as an organizational framework and a guide to an organization's own development of indicators and measures of cultural competence

CC must be integrated into other organisational domains of activity

Organisational values must be tackled first.

Structures, process and outcomes agreed for each of the subheadin

Information and data retrieval for cultural competence, Organisational flexibility, Planning, monitoring, evaluation: Client, community and staff inputs, Plans and Implementation, Collection and use of cultural competence data Communication: Understanding communication needs of clients, Culturally competent oral communication/written/other communication, Communication

Organisational infrastructure: Financial, Staffing, Technology, Physical facility characteristics, Linkages

Services/Interventions: Client family community input, Screening/assessment/care planning, Treatment and follow up 
ance framework for culturally competent commissioning and to assess the service impacts (see Table 1).

One US study evaluated how legal requirements in five US states for cultural competence in provider organisations are reflected in contract language, monitoring for adherence to the principles of cultural competency, and in the efforts to enforce adherence [25]. Although four states did include language support, for example, interpretation services, staff capacity and training, none of these contractual expectations were enforced, and there were no penalties for non-adherence.

\section{Quantitative Outcomes}

Only three studies gave quantitative outcomes [21-23]. These showed changes in 'intention to modify practice' following training (30\%) and actual changes in behaviour $(20 \%)$ following training [22]. There was significant (86\% of practitioners) satisfaction with the consultation model [21]; $48 \%$ reported better treatment, and 31\% expressed improved communication, empathy, understanding and therapeutic alliance. There were concerns that not all the recommendations could be followed due to limited resources. A lack of resources and recommendations that were unrealistic were sources of dissatisfaction among clinicians. Siegel et al reported high levels of training and education in administrative and service delivery aspects of service provision $(73-87 \%)$ as well as a commitment to culturally appropriate services [23]; $87 \%$ of the services were adapted or developed for specific cultural groups; $29 \%$ of these, provided culture-specific services; for $71 \%$ of these culture-specific services had been put in place in response to the perceived needs of clients in the community.

\section{Discussion}

The limited evidence recommends: a) specific processes and forms of learning for practitioners, b) in the context of a culturally competent provider that is c) commissioned and performance managed according to agreed benchmarks. The studies were based in the US or Canada, raising questions about the transfer of knowledge between these and other countries. For example, the managed care and insurance based service models in the US may not translate well to contexts where the services rely on public funding.

The histories of migration to each country will also differ; the emphases given in each country to specific forms of citizenship may favour the adoption of special services or propose that immigrants should assimilate and adapt themselves [27]. Furthermore, histories of colonial rule and positive expectations of each country's response to immigrants from the colonies may lead to disappointment and thwarted aspirations, alongside discrimination that all culminate in particular forms of discourse on cultural competency. For example, in the UK there has been an emphasis on discrimination and racism $[27,28]$. However, there are general lessons for work in a multi-cultural society and these will now be discussed.

\section{Individual level cultural competence}

The findings suggest that a culturally competent person is able to acknowledge, accept, and value the cultural differences of others. That is, such a person has the knowledge and skill that enable him or her to appreciate value and celebrate similarities and differences within, between, and among culturally diverse groups $[29,30]$. The 'LEARN' model emphasised more specific skills: Listen, Elicit, Assess, Recommend and Negotiate [22]. The voluntary desire to become culturally competent was seen to reflect an important general attitude towards work with culturally diverse groups [30].

Several sequential stages were identifiable in the pathway towards cultural competence. A developmental process was proposed moving from cultural awareness to improved cultural knowledge and improved skills through encounters $[19,20]$. This developmental process involved practitioners looking within themselves to reveal expectations about whether others should adapt to our institutional norms and culture [16]. This reflexivity is necessary to develop empathy through a better understanding of the patient's predicament [31], avoid assumptions and stereotypes [21], and to be aware of ones own attitudes and prejudices [32]. Empathy relies on precise communication of emotional experiences and worries, despite language barriers or communication through an interpreter. Indeed, with the right attitude to develop skills, and the aptitude to contain uncertainty, contradictions in communications can be positively harnessed to improve the outcome of therapies [33].

\section{Teaching \& Learning Methods}

The importance of training and education was highlighted. However, there was little information about appropriate content or learning methods in order to optimise learning and teaching impacts on practitioners' knowledge and skills, nor was there information on whether medical or other mental health practitioners require distinct approaches. Few publications evaluate teaching methods and the content of programmes for medical students and other health professionals. This is quite surprising considering there is acknowledgement of the need to examine policies and procedures regarding cultural sensitivity and competence to improve the experiences of black and ethnic minority services users [34].

Reviewing the literature reveals that there were no instances of enforced changes within mental health serv- 
ices. Materials to teach cultural competence maybe limited, but there are recommendations and materials available both in the US and UK to develop programmes [34]. Regrettably, as our review shows, few of these have been subjected to any stringent evaluation of outcomes. Different methods for teaching cultural competence include:

- Lectures: these convey lots of information and are cost effective.

- Case study discussion: these elicit many views, and participant interactions occur and challenge behaviours and attitudes.

- Role-play reveals hidden attitudes and challenges behaviours.

- Video materials and video feedback: this enables portrayal of many perspectives, demonstrates non-verbal communication, and raises awareness.

\section{Curriculum Content}

Welch divided training content into three areas, knowledge, awareness, and skills [35]. Knowledge focuses on the perspectives of illness and healing, learning about different views of illness and healing. Concepts and definitions of race, culture ethnicity, and the role of power are important to define. This also covers seeking to understand the family and community structures and functions. Awareness of difference and an ability to discern different health and illness beliefs were essential alongside challenging stereotypes and assumptions. Skills that were recommended focussed on social and language barriers in healthcare. An alternative approach is to use of film as a resource for cultural competency training. Like the studies that used case reports, consultation, and thoughtful discussion, the use of film and the arts can help explore the limitations of existing theories about race and ethnicity [36]. This approach brings to the fore the individuals' stereotypes that may shape assessment and clinical management recommendations. Policy and organisational constraints on individual practice can also then be discussed if they are witnessed to obstruct innovation.

\section{Organisational Cultural competence}

The literature revealed several domains of organisational cultural competency including attention to organisational values, training and communication. Cultural competence at the organisational level must be embedded in the infrastructure and ethos of any service provider. Culturally competent organisations actively design and implement services that are developed according to the needs of their service users. This involves working with others in the community, for example traditional healers, religious and spiritual leaders, families, individuals and community groups. Three studies included domains of assessment and performance management $[4,23,24]$. Clearly, this locates individual training and education in a more complex system of values, finances, policies and contracts $[16,25]$.

However, in the absence of evidence of effectiveness mandatory training is difficult to justify. Thus existing calls for training appear to rely on clinicians' extensive experience of benefits of training, concerns about the uncertainties involved in the care of culturally diverse groups including fears about accusations of discrimination, and political imperatives supported by anti-discriminatory legislation. Careful reading of established training manuals $[37,38]$ show these to be built on complex notions of race, ethnicity and culture, and the interaction with illness experience and behaviour and contexts. Pioneering work is based on experiences of the actual implementation of programmes in many countries in real clinical and service settings [39$41]$. In the absence of randomised trials, or clear specification of complex interventions to improve cultural competency, these forms of evidence should be used with care to establish the foundations for future research, training and service development [42].

\section{Conclusion}

Current mental health policies in culturally and racially diverse societies recommend that mental health professionals be cultural competent. However, the response from each country is in part dependent on the specific histories of immigration, and national attitudes towards migrants, citizenship and how to address racial and cultural integration. Cultural competency of care and services may be proposed in quite diverse ways depending on the local context. This mandates the needs for careful research and quality checks on what is proposed and implemented and applied in different countries [42].

This paper shows that although cultural competency training is important, the form it should take and the organisational performance frameworks to assess impacts are under developed. Most studies were exploratory, and few presented quantitative information. Future work should include randomised trials of complex interventions (teaching and organisational policies), alongside evaluations that include service user based assessment of benefit. In order to establish randomised trials, there needs to be agreement on and the development of appropriate outcome measures for educational and service level interventions. These may be distinct from performance measures at a service level, or commissioning frameworks. Investigations could also explore how 'values' in organisations may shift to produce more conducive environments in which anti-discriminatory practice can become embed- 
ded and so allow culturally competent care practices to flourish.

\section{Competing interests}

KB is Director of MSc Transcultural Mental Healthcare; NW is Co-ordinator and PE was an MSc student and formerly the administrator for the course. KM and DB: None. The author(s) declare that they have no other competing interests.

\section{Authors' contributions}

The work was supervised by KB and NW. PE obtained all the papers, which were extracted and checked by NW and $\mathrm{KB}$. KB wrote consecutive versions of the paper receiving comments from co-authors. DB and KM were external experts, provided supervision and expert advice, and commented on consecutive drafts of the paper. All authors have read and approved the final manuscript.

\section{References}

I. Anderson L, Scrimshaw S, Fullilove M, Fielding JE, Normand J: Culturally Competent Health Care Systems. American Journal of Preventive Medicine 2003, 24(3S):68-79.

2. $\mathrm{DH}$ : Inside Outside: Improving Mental Health Services for Black and Minority Ethnic Communities in England Department of Health, UK; 200I.

3. DH : Delivering Race Equality: A Framework for Action Department of Health, UK; 2003.

4. Health Resources and Services Administration: Cultural competence Works Health Resources and Services Administration. Conceptualizing Cultural Competence and Identifying Critical Domains 2001 [http://www.hrsa.gov/culturalcompetence/measures/ sectionii.htm]

5. Dein S: ABC of mental Health: Mental health in a multiethnic society. BM/ 2007, 3 I 5:473-479.

6. HealthFinder, US Department of Health and Human Services [http://www.healthfinder.gov/]

7. HealthScotland.com [http://www.healthscotland.com/]

8. London Health Commission [http://www.londonshealth.gov.uk]

9. Sainsbury Centre for Mental Health [http://www.scmh.org.uk]

10. Royal College of Psychiatrists [http://www.rcpsych.ac.uk]

II. Centre for Cross Cultural Health [http://www.crosshealth.com]

12. The Cross Cultural Healthcare Program [http://www.xculture.org]

13. American Medical Student Association [http://www.amasa.org/div]

14. National Centre for Cultural Competence [http://wwwl I.georgetown.edu/research/gucchd/nccc/]

15. Office of Minority Health [http://www.omhrc.gov/clas]

16. Mann JJ, Apter A, Bertolote J, Beautrais A, Currier D, Haas A, Hegerl U, Lonnqvist J, Malone K, Marusic A, Mehlum L, Patton G, Phillips M, Rutz W, Rihmer Z, Schmidtke A, Shaffer D, Silverman M, Takahashi Y, Varnik A, Wasserman D, Yip P, Hendin H: Suicide prevention strategies: a systematic review. JAMA 2005, 26; 294( I 6):2064-74.

17. Bhui K, Stansfeld S, Hull S, Priebe S, Mole F, Feder G: Ethnic variations in pathways to and use of specialist mental health services in the UK. Systematic review. Br J Psychiatry 2003, I 82:105-16.

18. Frusti DK, Niesen KM, Campion JK: Creating a culturally competent organization: use of the diversity competency model. J Nurs Adm 2003, 33(I):31-8.

19. Kim-Godwin YS, Clarke P, Barton L: A model for the delivery of culturally competent community care. Journal of Advanced Nursing 200I, 35(6):918-925.

20. Hadwiger S: Cultural Competence Case Scenarios for Critical Care Nursing Education. Nurse Educator 1999, 24(5):47-5I.
21. Kirmayer LJ, Groleau D, Guzder J, Blake C, Jarvis E: Cultural consultation: a model of mental health service for multicultural societies. Can J Psychiatry 2003, 48(3): | 45-53.

22. Ferguson J, Keller D, Haley H, Quirk M: Developing Culturally Competent Community Faculty: A Model Program. Academic Medicine 2003, 78( I 2): I 22 |-8.

23. Siegel C, Haugland G, Chamber E: Performance Measures and Their Benchmarks for Assessing Organisational Cultural Competency in Behavioural Health Care Service Delivery. Adm Policy Ment Health 2003, 3 I (2): I 4I-70.

24. Kondrat ME, Greene G, Winbush G: Using benchmarking research to locate agency best practices for African American clients. Adm Policy Ment. Health 2002, 29(6):495-5I8.

25. Stork E, Scholle S, Greeno C, Copeland VC: Kelleher, Monitoring and Enforcing Cultural Competence in Medicaid Managed Behavioural Health Care. Mental Health Service Research 200I, 3(3): 169-177.

26. Office of Minority Health (USA) Assuring Cultural Competence in Health Care: Recommendations for National standards and an Outcomes-Focused Research Agenda Federal Register: December 22. 2000, 65(24780865-80879 [http://www.omhrc.gov/ Assets/pdf/checked/ Assuring Cultural Competence in Health Care-1999.pdf]. Office of Minority Health (USA)

27. Kirmayer LJ, Minas $\mathrm{H}$ : The future of cultural psychiatry: an international perspective. Can J Psychiatry 2000, 45(5):438-46.

28. Bhui K: Racism \& Mental Health. Edited by: . Jessica Kingsley Publishers. London; 2002.

29. Singh N: To Value and Address Diversity: From Policy to Practice. Journal of Child and Family Studies 2002, I I ( I):35-45.

30. Campinha-Bacote J: Many Faces: Addressing Diversity in Healthcare. Online Journal of Issues in Nursing 2003, 208(I): [http:// www.transculturalcare.net/].

31. Warren B]: The Interlocking Paradigm of Cultural Competence: A Best Practice Approach. Journal of the American Psychiatric Nurses Association 2002, 8(6209-2 I 3 [http://www.apna.org].

32. Kai J, Spencer J, Wilkes M, Gill P: Learning to value ethnic diversity - what why and how? Medical Education 1999, 33:616-623.

33. Comas-Diaz L, Jacobsen FM: Ethnocultural transference and counter-transference in the therapeutic dyad. American J. Orthopsychiatry 1993, 6 I(3):392-402.

34. Loudon R, Anderson M, Gill P, Greenfield S: Educating Medical Students for Work in Culturally Diverse Societies. JAMA 1999, 282(9):875-80.

35. Welch M: Concept paper : Culturally Competent Care, National Advisory Committee, Office of Minority Health/Office of Public Health Sciences, Department of Health and Human Services 2002 [http://www.culture andhealth.org.cccm/progress.welch.pdf].

36. Burgan D: Using Film and Literature for Cultural Competence Training. Psychiatric Bulletin 2003, 27:427-428.

37. Campinha-Bacote J: The Process of Cultural Competence in the Delivery of Health Care Services: A Culturally Competent Model of Care 3rd edition. Cincinnati, OH: Transcultural C.A.R.E. Associates; 1998.

38. Cross TL, Bazon BJ, Dennis KW, Isaacs MR: (1999) Reducing disparities through culturally competent Health Care: An Analysis of the Business Case. In Towards a Culturally Competent System of Care. Quality Management in Health Care Volume 10. Issue 4 Washington DC, Georgetown University Child Development Centre cited in Brach, C. \& Fraser, I; 2002:I5-28.

39. Fassin D: An anthropological hybrid: the pragmatic arrangement of universalism and cultureless in French Mental Health Care. Transcultural Psychiatry 2005, 42(3):347-366.

40. Fernando S: Multicultural Mental Health Services for Minority Ethnic Communities in Britain. Transcultural Psychiatry 2005, 42(3):420-436.

4l. Hung-Tat L: The Hong Folk Experience: working with ethno cultural communities in Toronto 1982-2002. Transcultural Psychiatry 2005, 42(3):457-477.

42. De Jong J, Van Ommeren M: Mental Health Services in a Multicultural Society: Interculturalization and its Quality Surveillance. Transcultural Psychiatry 2005, 42(3):437-456. 


\section{Pre-publication history}

The pre-publication history for this paper can be accessed here:

http://www.biomedcentral.com/1472-6963/7/15/prepub

Publish with Biomed Central and every scientist can read your work free of charge

"BioMed Central will be the most significant development for disseminating the results of biomedical research in our lifetime. " Sir Paul Nurse, Cancer Research UK

Your research papers will be:

- available free of charge to the entire biomedical community

- peer reviewed and published immediately upon acceptance

- cited in PubMed and archived on PubMed Central

- yours - you keep the copyright 